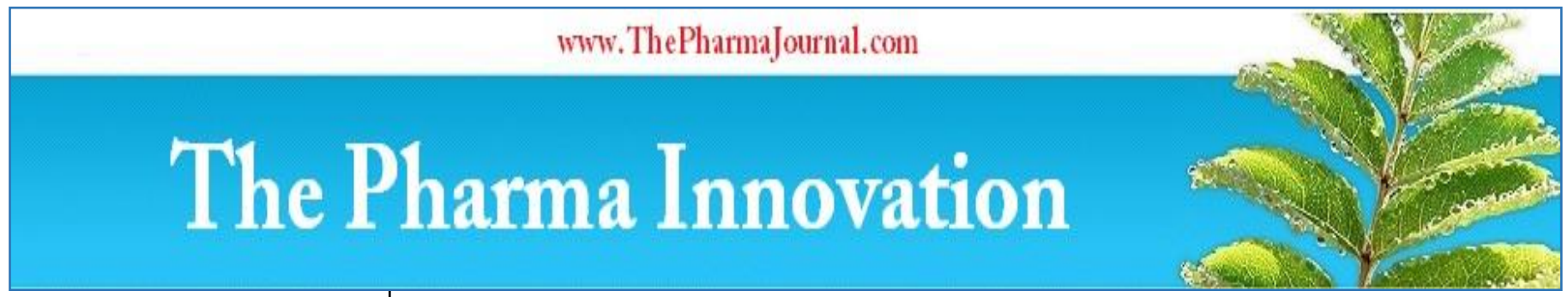

ISSN (E): 2277 - 7695

ISSN (P): 2349-8242

NAAS Rating: $\mathbf{5 . 0 3}$

TPI 2020; 9(6): 542-545

(C) 2020 TPI

www.thepharmajournal.com

Received: 14-04-2020

Accepted: 16-05-2020

\section{Kasinam Doruk}

College of Agriculture, Central Agricultural University, Imphal, Manipur, India
Corresponding Author:

Kasinam Doruk

College of Agriculture, Central

Agricultural University, Imphal,

Manipur, India

\title{
Corona pandemic: A lesson learned and preparedness for future crisis
}

\section{Kasinam Doruk}

DOI: https://doi.org/10.22271/tpi.2020.v9.i6h.4820

\section{Abstract}

As the ripple of COVID-19 seen around the globe, it's forcing humankind to innovate and change the way we work and live. The upside of where we find ourselves right now is that individuals and corporations will be more resilient in a post-COVID-19 world. It can act as a "WAKE-UP CALL FOR ALL OF US, AS A INDIVIDUAL, AS A SOCIETY AND AS A COUNTRY. "life after Covid-19 should not be the same. It will call for a change in priorities, in focus and in the way we do things.SARSCOV-2 (Severe acute respiratory syndrome coronavirus -2), The virus that causes Covid-19,first emerged in Wuhan china, in December 2019.The virus caught the global community off guard, and it's future course is still unpredictable, it was on March 11, 2020,that the world health organization (WHO.,) ${ }^{\text {[5] }}$ declared a global pandemic. There is no crystal ball to tell us what the future holds and what the "end game" for controlling this pandemic will be. Billions of people are in lockdown, unable to visit one another, unable to go work, unable to attend school, unable to meet one another in public places. People around the world are in desperate straights, struggling at home, in care homes and intensive care units, dying of the same cause, separated from their loved ones in their hours of need. At times of existential danger, we instinctively desire to be close to our family and friends, hold their hands and embrace them but now we are forbidden to do so, for every act of physical contact, every expression of physical lovingkindness and compassion could bring illness and death.

Keywords: Covid-19, pandemic, preparedness, telemedicine, digital didactic

\section{Introduction}

The Covid-19 pandemic demonstrates to us the value of freedom - the freedom to move, to be with those we love, to live in dignity and security - for ourselves and for those around us, from our loved ones to the refugees and the downtrodden. It shows us the importance of recognizing the true purpose of all our businesses and economies, our political parties and governments, our local civic associations and our international organizations, our conventions and ideologies, and all our other systems: namely, to serve human needs and purposes. We are currently in the midst of a worldwide trial that has changed our lives beyond recognition. Effective governance of pandemics involves preparedness, response and recovery at local, national and international levels as the saying strategies "The difficulties and problems of the villages can only be resolved by the villagers themselves" - zarina.

www.health.gov.au., ${ }^{[1]}$ Digital didactic and online learning can be protracted for months. Telemedicine, and in particular teleopthalmology, needs to be implemented. Also, in the future, infectious diseases will be probably included amongst the most important health hazards along with anti-microbial resistance in addition, timely identification, efficient diagnosis, rapid isolation and clinical management would remain in the forefront. The time has come to re-evaluate the appropriate goal of business; the goal of our economic activities; the goal of our ideologies and social conventions; and the goal of our local, national and international governance structures. The pandemic shows us that the goals of all these domains must always the same. contributing to the fulfillment of human needs and purposes. This requires us to cooperate locally when we face local challenges, nationally when we face national challenges, and globally when we face global challenges.

Smart working and staggered shifts may have to be adopted to mitigate COVID-19 transmission in the future. 


\section{Here are some of the lesson for preparedness in future as below}

Lesson One- War like preparation required on healthcare front: Future healthcare systems should be war-prepared to battle pandemics whenever they breakout.

We have near-complete knowledge on tackling major killers like heart ailments, cancer, lifestyle diseases, AIDS etc., but not a virus. We also need to critically look at our healthcare ecosystem, especially the critical care segment. Hence, when a pandemic strikes, there should be an action plan that can be implemented in the shortest time frame - one that can balloon our healthcare infrastructure by removing bottlenecks and creating more critical care units and isolation centres without affecting non-pandemic critical care patients. This can be done by involving the private sector - both in the healthcare segment and hospitality sector which can become isolation units.

Lesson Two- We need to set 'early warning systems' in place in the society: Unlike in the past, viruses in the $21 \mathrm{st}$ century not only are 'hyperactive', but also leave their tales of devastation with 'viral speed'. This is because of globalisation. Again, this is not new.

In the seminal book of $A B$ Alfred $W$ Crosby jr "The Columbian Exchange', AB Alfred W Crosby Jr writes: "When the isolation of the New World was broken, when Columbus brought the two halves of the planet together, the American Indian met for the first time his most hideous enemy; not the white man nor his black servant, but the invisible killers which these men brought in their blood and breath." Within a span of just 70 odd years, 80-100 million natives perished because of the disease brought by Europeans from across the seas: smallpox, influensa, diphtheria. Today, it will not take 70 odd years, but just a few months to leave thousands dead due to an unknown virus. Hence, the second lesson is that we cannot stop globalisation with countries interconnected by air, but when an unknown virus breaks its barriers and jumps to humans, there should be warning bells early enough. In the case of COVID-19, that did not happen. Had there been an early warning system in place and had nations isolated themselves, the virus could have been contained in small pockets.

\section{Lesson Three-more contactless interfaces and interactions}

There was a time not too long ago that we were impressed by touch screens and all they enabled us to do. COVID-19 has made most of us hyper-aware of every touchable surface that could transmit the disease, so in a post-COVID-19 world, it's expected that we'll have fewer touch screens and more voice interfaces and machine vision interfaces. Prior to the pandemic, we saw the rollout of contactless payment options through mobile devices. However, with the increase in people wanting to limit what they touch, an option to pay for goods and services that does not require any physical contact is likely to gain traction. Machine vision interfaces are already used today to apply social media filters and to offer autonomous checkout at some stores. Expect there to be an expansion of voice and machine vision interfaces that recognize faces and gestures throughout several industries to limit the amount of physical contact. Social distancing should become a norm, part of our regular habits. When a new virus comes knocking, there should be a self-imposed social distancing to break the chain. Even in the absence of a virus, it is better to observe social distancing as a part of life.
Intimacy may be good and may reflect part of one's culture, but distancing, without offending the other, is the best. (CIDRAP, 2020) ${ }^{[2]}$

Lesson four-Swachh Bharat should become a norm for 100 per cent Indians. India has to evolve a mechanism to maintain hygiene and cleanliness. For this, the urge should come from within. Parts of cities and towns are buried to the nose with garbage and filth. This has to end, so too our unbridled drive to pollute air and water in the name of economic progress and gains.

Lesson Five-A guideline for at-risk people-elderly and patients with comorbidity- should be in place and in practice, Whenever there are signs of a pandemic, India should be able to isolate the elderly, patients with comorbidity and children who are either underweight and malnourished. For this, what is of paramount importance is a robust health surveillance system at the state level and a constantly updated registry of population on a national scale. Unless the vulnerable sections are pre-identified through strong data collection, states and nations would not only invite trouble but also leave the doors wide open for the virus to enter.

Lesson Six- Need to promote original Research and Development and strengthen our Drug \& Vaccination Development Programme further. Coronavirus has had a happy flip side too. It has shown the world the strength of our pharma segment. India could export life-saving drugs to major countries, including the developed world. But India cannot rest on its laurels. There is a need to further strengthen our Drug \& Vaccine Development Programme by speedtracking vaccine and drug development when a pandemic strikes.

\section{Artificial intelligence-enabled drug development}

The faster we can create and deploy an effective and safe drug to treat and a vaccine to prevent COVID-19 and future viruses, the faster it will be contained. Artificial intelligence is an ideal partner in drug development because it can accelerate and complement human endeavors. Our current reality will inform future efforts to deploy AI in drug development.

\section{Telemedicine}

Have you received the emails from your healthcare professionals that they are open for telemedicine or virtual consultations? To curb traffic at hospitals and other healthcare practitioners' offices, many are implementing or reminding their patients that consultations can be done through video. Rather than rush to the doctor or healthcare center, remote care enables clinical services without an in-person visit. Some healthcare providers had dabbled in this before COVID-19, but the interest has increased now that social distancing is mandated in many areas.

\section{Lesson Seven-Push our indigenous diagnostics} manufacturing to make it sufficient for Indian Needs. COVID-19 has exposed India's unpreparedness in having rapid testing kits and PPEs. Along with developing frontline vaccines, the lesson that COVID-19 has taught is the need to have millions of testing kits. This is because, when a pandemic strikes, the only way to check community spread is 
testing. Regarding PPEs, India should look inwards. Massive garment export units in Tirupur (Tamil Nadu), Karnataka and other places can become manufacturing units of PPEs and also eye exports.

Lesson Eight-our govt. need to make appropriate provisions for supporting the Bottom of pyramid population in case of such calamities

A pandemic always hard-knocks and downs economies world over. COVID-19 is no exception. 2020 could be the worst year for the global economy in nearly a century.

Hoimonty et al., ${ }^{[7]}$ The global economy is expected to contract by 3 per cent this year because of economic damage from the coronavirus pandemic — the steepest downturn since the Great Depression of the 1930s, according to the International Monetary Fund.But in future, India should have a strong mechanism to take care of the people at the base of the pyramid who actually oil and run the wheels of the nation's economy. Only they can put the economy back on track. Nobel laureates Amartya Sen and Abhijit Banerjee and former RBI Governor Raghuram Rajan recently penned a piece in The Indian Express saying: As it becomes clear that the lockdown will go on for quite a while, the biggest worry right now, by far, is that a huge number of people will be pushed into dire poverty or even starvation by the combination of the loss of their livelihoods and interruptions in the standard delivery mechanisms. That is a tragedy in itself and ...we need to do what it takes to reassure people that the society does care and that their minimum well-being should be secure. (Anderson et al.) ${ }^{[3]}$

The bottomline is that India has to have a robust action plan when a pandemic strikes - a plan that is creative, disciplined and, above all, sensitive.

\section{Lesson 9: Strengthened digital infrastructure}

COVID-19 caused people to adapt to working from home and in isolation. By forcing our collective hand to find digital solutions to keep meetings, lessons, workouts, and more going when sheltering in our homes, it allowed many of us to see the possibilities for continuing some of these practices in a post-COVID-19 world. For me, I realized that traveling to other countries just for a meeting isn't always essential, and I have learned that video calls for all kinds of meetings (yes, even board meetings) can be equally effective.

EG. Indian govt has developed "mygov corona helpdesk, live HelpDesk: https://wa.me/919013151515 ...this can be done only with the presence of internet.

\section{Lesson 10: Better monitoring using IoT (Internet of things (IoT) and big data}

We see the power of data in a pandemic in real-time. The lessons we are receiving from this experience will inform how we monitor future pandemics by using internet of things technology and big data. National or global apps could result in better early warning systems because they could report and track who is showing symptoms of an outbreak. GPS data could then be used to track where exposed people have been and who they have interacted with to show contagion. Any of these efforts require careful implementation to safeguard an individual's privacy and to prevent the abuse of the data but offer huge benefits to more effectively monitor and tackle future pandemics.

EG.2. Aarogya Setu is a mobile application developed by the Government of India to connect essential health services with the people of India in our combined fight against COVID-19. The App is aimed at augmenting the initiatives of the Government of India, particularly the Department of Health, in proactively reaching out to and informing the users of the app regarding risks, best practices and relevant advisories pertaining to the containment of COVID-19.

Eg. The Ministry of AYUSH presents the "Ayush Sanjivani" mobile application for understanding the measures adopted by public for enhancing immunity and keeping themselves healthy in the difficult COVID-19 situation.

\section{Eg. Google / Apple contact tracing project U.S.A}

How We Feel, Private Kit: Safe Paths, Covid Watch, coEpi, NOVID U.K: NHS COVID-19, COVID-19 Apple / Google App,

\section{Lesson 11: More digital events}

Organizers and participants of in-person events that were forced to switch to digital realize there are pros and cons of both. While I don't predict that in-person events will be replaced entirely after COVID-19, I do believe event organizers will figure out ways the digital aspects can complement in-person events. I believe a steep rise in hybrid events where parts of the event take place in person, and others are delivered digitally.

\section{Lesson 12: More online e-commerce}

Although there were many businesses that felt they had already cracked the online shopping code, COVID-19 taxed the systems like never before as the majority of shopping moved online. Businesses who didn't have an online option faced financial ruin, and those who had some capabilities tried to ramp up offerings. After COVID-19, businesses that want to remain competitive will figure out ways to have online services even if they maintain a brick-and-mortar location, and there will be enhancements to the logistics and delivery systems to accommodate surges in demand whether that's from shopper preference or a future pandemic. (Comac et al.,) [6]

\section{Lesson 13: Increased reliance on robots}

Robots aren't susceptible to viruses. Whether they are used to deliver groceries or to take vitals in a healthcare system or to keep a factory running, companies realize how robots could support us today and play an important role in a post-COVID19 world or during a future pandemic.

\section{Lesson 14: Rise in esports}

Sporting events, organizations, and fans have had to deal with the reality of their favorite past-times being put on hold or seasons entirely canceled due to COVID-19. But esports are thriving. There are even e-versions of F1 car racing on television, and although it might not be the same as traditional Formula 1 racing, it's giving people a "sports" outlet. Unlike mainstream sporting events, esporting events can easily transition online. Similarly to events, I believe more hybrid sports coverage where physical events are complemented with digital offerings.

\section{Lesson 15: Co-ordination and proper plans}

To provide coordinated management of any pandemic, national public health, emergency management mechanisms including a multidisciplinary national coordination cell or incident management structure should be activated, with the 
engagement of relevant ministries such as health, foreign affairs, finance, education etc. Develop operational plans to address the pandemic. plans should include capacity assessments and risk analysis to identify high risk and vulnerable population. plans should include civil society and national NGOs to extend the reach of public health and socioeconomic intervention. (Kissler et al.) ${ }^{[4]}$

We must understand the strength of the current entity and also to the strength of the future entity, in that resilience is the continuing ability to use internal and external resources successfully to resolve issues.

\section{Conclusion}

So I conclude by entailed that COVID-19 might be taxing our systems and patience, but it's also building our resilience and allowing us to develop new and innovative solutions out of necessity. In a post-COVID-19 world, I hope we will take the lessons handed to us by our time dealing with the virus and make our world a better place. I also believe this pandemic has given us reminders and insights about technological progress to help us fight future adversaries, may it be invisible to eyes or not. I just hope that everything will turn out well.

\section{References}

1. www.health.gov.au. (2020) Australian health sector emergency response plan for Novel Coronavirus (Covid19).

2. COVID-19, The CIDRAP Viewpoint, 2020.

3. Anderson RM, Heesterbeek H, Klinkenberg D. How will country-based mitigation measures influence the course of the COVID-19 epidemic

4. Kissler SM, Tedijanto C, Goldstein E. Projecting the transmission dynamics of SARS-CoV-2 through the postpandemic period. Science, 2020.

5. WHO, COVID-19 strategy update. Avenue Appia 20 1211 Geneva 27 Switzerland WHO in Emergencies: www.who.int/emergencies/en.

6. Comac B, Simon A, Patrick R, Jamle W. Resilience in the Face of Uncertainty: Early Lessons from the COVID19 Pandemi, 2020.

7. Hoimonty M, Hossain MM, Anupom D. Geriatric care during public healthe mergencies: lessons learned from novel corona virus disease (Covid-19) pandemic. Journal of gerontological social work. 